\title{
Annual symposium of the SSIEM 2010
}

\author{
Turgay Coșkun
}

Published online: 31 May 2011

(C) SSIEM and Springer 2011

The 2010 Annual Symposium of the SSIEM took place in İstanbul, without a doubt one of the most beautiful cities in the World, between August 31 and September 3. A total of 1450 attendees from 70 different countries participated, and we cordially invited SSIEM Family Members with the popular slogan "Let's meet where the continents meet". We believed that this meeting would take its place in the history of the SSIEM as one of the meetings with the highest number of the participants.

On the 31 st of August, the precongress ERNDIM meeting, the ERNDIM Diagnostic Proficiency Testing (DPT), the Nutrition and Dietary Treatment Workshops, and the JIMD Editorial Board Meeting were held concurrently. SSEIM Council and Corresponding Members also met during lunch time on the same day.

The official opening ceremony with the theme of "Inborn Errors of Metabolism in the 'Omics' Era" occurred in the afternoon. Within the framework of the meeting, seven plenary sessions with the titles of "Future of Omics", "New Era in PKU Research", "Posttranslational Modification of Proteins", "Inborn Errors of Bile Acid Metabolism", "Proteins: Structure and Function, Proteomics", "Inborn Errors of Metabolism and the Kidney", and "Novel Approaches in Lysosomal Storage Disorders" took place. Additionally, 14 parallel sessions in which 84 scientists had the chance to share and discuss their most recent research findings with the audience, took place throughout the meeting.

The SSIEM 2010 meeting was significant for the occurrence of two "firsts". One of these was "Poster Walk

\section{T. Coşkun $(\bowtie)$}

Division of Pediatric Nutrition and Metabolism,

Hacettepe University Faculty of Medicine,

Ankara, Turkey

e-mail: tcoskun@hacettepe.edu.tr with Snacks and Drinks" that offered more opportunities for participants to evaluate all posters in detail. Further, the Adult Metabolic Physicians Group members held their inaugural meeting during the Symposium.

After a memorable introduction by Prof. Cornelis Jakobs, Chairman of the SSIEM, meeting participants had the honor of Prof. Bridget Wilcken of Australia as presenter of the "Komrower Memorial Lecture", entitled "Newborn screening: How are we travelling? Where might we get to?".

The scientific component of the meeting concluded with the presentation of awards for the best presentations selected from those offered in the "Late Breaking News" session. This was yet another "first" for the Istanbul Symposium.

Participants of the SSIEM 2010 İstanbul meeting reported a very enjoyable social program. During the opening ceremony, a famous Turkish pianist and composer, Tuluyhan Ugurlu, played beautiful selections from the album "World Capital City İstanbul". A simultaneous slide show guided participants through an overview of Istanbul from the past to the present. The evening welcome reception took place at the nearby Military Museum, where participants were welcomed by the "Old Ottoman Band" called "Mehter".

On the third day of the meeting, time was allocated for the traditional SSIEM social outings. The majority of participants enjoyed the boat tour over the Bosphorus, accompanying the natural and historical beauties of İstanbul on both banks of the Bosphorus under sunny skies.

The Symposium dinner was a nice blend of both traditional gala dinner and party. Participants enjoyed samples of Turkish cuisine, supplemented with dancing and music from many different countries.

As the local organizing committee, our goal was to organize an excellent scientific and social meeting, while ensuring each participant an enjoyable and unforgettable stay in Istanbul. We believe we reached this goal. 
However, without the active participation of many members of our Society, the meeting would not have been the success that it was. I would like to thank all Council Members for their guidance in the preparatory phase of the meeting, and we all must express our thanks to the sponsors for their generous support, without which our meeting would not have been possible. My special thanks go to our PCO, and particularly Ms. Bahar Ceyhan, Ms. Seda Koçak and Mr. Harun Tulunay for their outstanding efforts throughout the Symposium. Finally, I acknowledge and thank all participants whose active participation ensured the success of our Symposium.

We hope to see members of the SSIEM Family, either in İstanbul or some other beautiful part of Turkey, in the near future.

Turgay Coșkun

(on behalf of the Local Organizing Committee) 